\title{
Specificity of human capital in the conditions of digital transformation of business organizations
}

\author{
Andrey Polyanin ${ }^{1}$, , Tatyana Golovina ${ }^{1}$, Irina Avdeeva ${ }^{1}$ and Yulia Vertakova ${ }^{2 *}$ \\ ${ }^{1}$ Central Russian Institute of Management, Branch of RANEPA, 5A, Boulevard Pobedy, Orel, \\ 302028, Russia \\ ${ }^{2}$ Southwest State University, South-West State University, 50 let Oktyabrya str., 94, Kursk, 305040 \\ Russia
}

\begin{abstract}
In Russia have emerged all the necessary prerequisites for the digital potential development and digital economy growth rates acceleration. The country has a sufficient intellectual and scientific base, supported by a good system of secondary and higher education. At the same time, the digital economy requires global production renewal, all levels staff retraining and rapid innovative management methods implementation. By all means in conditions of such economy highly skilled and highly paid personnel who has the opportunity to develop and to invest their human capital are certainly needed. The necessity to study the problems associated with the changes of quality of human capital influenced by the digitalization of the economy and determining the vectors for their solution is due to the discrepancy between the skills provided by the education system and required by the new economy, integration and globalization processes that dictate the need to search for modern methods, tools and management solutions for perfection of the formation system and use of human capital. Under the digital economy, the country's competitiveness is determined in the first instance by the accumulated and developed human capital, possessing various network and digital competencies at various levels: global, state, corporate and socioindividual.
\end{abstract}

\section{Introduction}

The development of the scientific thought regarding the issues of the formation and use of human capital demonstrates the growing relevance of problems related to perfection of the management of formation and development processes of human potential that will ensure effective results and development of enterprises, industries and the economy of the country as a whole.

In connection with the transformation of socio-economic processes, the digital development of the economy, the reorganization of the public administration in Russia, arise many new phenomena requiring the research of both fundamental and applied nature. At the present time, there is no clear methodological support that reveals the socio-

* Corresponding author: vertakova7@yandex.ru 
economic aspects of human capital in the conditions of digital transformation of entrepreneurial organizations. The effective use of human resources and their potential contributes to the development and strengthening of the ties between science and business, to the improvement of scientific research, to the development of creative abilities of personnel and to the adoption of innovative digital solutions.

Much attention to the problems of formation and use of human capital is paid by both foreign and domestic scientist economists. Socio-economic issues of human potential are considered by foreign scientists such as Harrod R., Keynes J., Gorz A., Hardt M., Negri A., Becker G., Shultz T., Kuznets C., and by domestic economists Habibullina Z. R., Kapitsa S. P., Zernov V. A.

A particular contribution to the study of human capital and its transformation under the digitalization of economic processes was made by the following scientists and professional communities: Boston Consulting Group, International Bank for Reconstruction and Development, Regent T. M., Shedko Yu. N., Chaynikov V. V.

At the same time, in the existing publications and scientific developments, the issue of human capital and human resources management is mainly considered in general, without studying the problems of ensuring innovative processes of the formation, use and development of human potential, taking into account the needs of digital economy.

Human capital in the countries with the developed digital economy is the main productive factor ensuring creation of new technologies, development of innovative industries, dynamic development of the economic and social spheres.

\section{Purpose of the study}

The purpose of the research is to study the problems of the socio- economic interface of human capital in the current economic conditions and to justify the organizational and management measures for its development and effective use.

\section{Key findings}

Nowadays all the participants of the economic system recognize the inevitability of digital transformation. It is conditional on both new opportunities and risks, which may lead to the digitalization rejection. This includes the liquidation and creation of jobs, retention of talents, support of digital companies - "champions" and, as a consequence, GDP growth.

In Russia, there is an animated discussion on the problem of the transition of the world and national system of management to the digital economy. The problems of transition to a postindustrial system of management and its development have shaped up in the form of digital economy in expert assessments of the scientific and public elite. At the same time, the "digital economy" concept content is still blurred, despite the fact that it was introduced in scientific use back in 1995 by the American information scientist N. Negroponte [7]. And the World Bank reports of 2016-2017 "Digital dividends" and "Prospects of obtaining of digital dividends in the Eurasian Economic Union" [20] do not give a clear definition here either.

It is not surprising that it is possible to meet diametrically opposed opinions of Russian scientists when interpreting this concept. Thus, on the one hand, academician S. Glazyev talks about the digital economy as a new sixth technological paradigm. The scientist notes: "The fifth technological paradigm is based on the application of microelectronics achievements in the management of physical processes at the micron level. The sixth technological paradigm is based on the use of nanotechnologies, operating at the level of a billionth of a meter and capable to change the structure of substance at the molecular and 
atomic levels, giving it fundamentally new properties, as well as to penetrate in the cellular structure of living organisms, modifying them"[4]. On the other hand, a well-known scientist V. Katasonov describes the modern digital economy as a new financial speculative bubble, which is formed on the same principles as in 2000 by a sharp fall of market data of numerous IT companies, and in 2008 by a mass bankruptcy of natural persons on mortgage lending and mortgage securities market $[10,11]$.

According to the authors, these two points of view, despite their opposite positions, reflect different aspects of the digital economy, the establishment and the development of which, like everything new, is extremely contradictory. The latter is not surprising, in view of the fact that it is in the virtual space that the spontaneous market processes are practically not regulated by the state, the speculations with the use of information technologies, often taking the form of financial pyramids and various fraudulent schemes, are not limited, the shadow sector is actively developing. The state in a whole has not yet developed a system to regulate the virtual space, mechanisms of digital technologies tracking. One can say that in a virtual space, economic phenomena and processes are largely subordinated to the principle of the era of original capital accumulation in the XVI - XIX centuries - formation of huge incomes by a very tiny number of people by means of ruin of a large part of the population. However, the main difference of this principle impact under the modern conditions consists in the fact that these economic phenomena and processes occur outside the national borders.

The authors understand by the digital economy the system of relations between business entities and management system built on them, where a person is partially eliminated from the decision-making processes by means of the use of technologies of digital data automatic processing, which leads to the change not only of technological properties, but also of the economy structure in a whole [21].

Of course, digital technologies is the thing of the future, as they contribute to the growth of labor productivity, to the reduction of the production and capital goods prime cost, to the substitution of labor for the capital, to the increase of the logistics and global networks efficiency.

It is no coincidence that analysts of the consulting company Boston Consulting Group (BCG) predicted that by 2035 the digital economy could reach 16 trillion dollars in cash. [20].

The evolution of the change of technological paradigma up to the present time reflects an exponential growth of the requirements to a person, whose knowledge, competence, qualification, ability to self-development influence increasingly both national wealth and the company`s capitalization. Today, the most profitable is not the industrial sector, but IT companies (Chevron, General Motors, General Electric, etc.). In the capitalization of such companies, the decisive role is played by human capital, as a significant part of their market value accrue to intellectual property. For example, in balance of Alphabet company, the value of physical assets amounts to $\$ 40$ billion, while its market value is $\$ 545$ billion [15].

Digital technologies change everywhere people`s life, forming a virtual and augmented realities, built in usual daily routine. At the present time, the development of human society has entered the early stage of the digital industrial revolution, which is characterized by the beginning of the transformation of traditional industries based on new digital technologies. Expanding of the application of additive technologies, big data transforms the means of production not only in industry, but also in agriculture and the service industry.

Advances in the field of robotics industry and artificial intelligence will contribute to the further promotion of this transformation and to the integration of digital technologies in all phases of social reproduction. Traditional industrial processes become intellectually interconnected based on digital production technology or digital management methods. In different countries, the promotion of digital technologies is occuring at an uneven pace, 
which is due to differences in the level of development of scientific and technical progress and to the quality of human capital. Nevertheless, by integrating into production relations, the process of digitalization comes laden with all the signs of irreversibility, when socioeconomic systems tend to the most probable scenario of development with the greatest opportunities to be realized, forming an objective process of the formation of a new quality of the system. This transformation contains significant threats along with the positive effects of the digital economy formation, such as: "Internet of things"; implants created with the use of bioprinting; unmanned vehicles, etc.

As an example of a short term threat we can state structural unemployment. Many analysts predict its mass proportions, especially among people without education or having a secondary special education (SSE). According to the researches of the American economist D. Autor, changes in employment related to widespread automation will primarily bear on the employees of medium qualification, as their functionalities contain a sufficient number of template functions so that they can be automated, and these specialists are highly paid that the automation is economically feasible [16,17].

Digital technologies will continue to change existing jobs and create new ones. Artificial intelligence will little by little displace routine intellectual work. These processes will deepen and change not only the content of labor functions, but also the very organization of labor. At the present stage of the formation of the digital economy, it is impossible to unequivocally assess the consequences of this process due to its great complexity and versatility, but as the productive forces develop and the new quality of production relations develops, we will be able to understand better what knowledge and skills will be required by the new economy [12].

However, even now it is definitely possible to forecast the release of low-skilled labor force, since it is these jobs that will be primarily automated and replaced by robots. The problem of structural unemployment as a result of the transition to the digit will become relevant for both developed and developing countries [14].

Another important impact factor on the quality of human capital which is the speed of digital transformation of human society should also be highlighted. It is rather important and the process of digitalization will be accelerated exponentially, which in the nearest future will result in a shortage of personnel of new professions or in a change of competencies within existing qualifications. The transfer to digital technologies of a part of production processes will demand from workers to acquire new skills as the content of their labor functions changes, and the lack in the labor market of sufficient quantity of workers with the right skills will give to enterprises a greater incentive to cooperate with higher education institutions that provide the opportunity for additional professional education.

At the same time, the financing of the social sphere in Russia is based on a residual principle, which is not sufficient not only for development, but even for leveling of processes of degradation. What contributes to the formation of a model of the narrowed reproduction of human capital, both quantitatively (birth rate, mortality rate, population emigration and immigration levels, etc.) and qualitatively (literacy rate, number of people with higher education, number of people with alcohol dependency and patient with drug dependence, etc.).

Certainly, in the developed countries there are problems with the reproduction of human capital, because in general the institutions of social sphere fall behind the digital technologies and require serious modernization. But, at the same time in Russia, unlike developed countries, along with the problems of low financing, there are huge disproportions in the structure of production in favor of the sphere of circulation, which over the years only increase. Such disproportions in the economy lead to the simplification of the labor demand structure. So, Gimpelson V. E. notes that half of the aggregate and 
realized demand for labor is concentrated in only 27 occupations [4]. However, among these professions there is not a single that would relate to technical progress.

It is assumed that in Russia the number of specialists with a higher education in the field of information and telecommunication technologies will increase from 2024 by 120 thousand people annually. Universities, technical schools and colleges will produce each year 800,000 more IT specialists. Thanks to this fact, the share of population having digital skills will grow up to $40 \%$ [20].

However, the disproportions are also present in the system of distributive relations. The huge concentration of property in the hands of a small group of individuals leads to disproportions in the distribution of factor incomes, where payment for work is extremely understated. Chayanov A. V. has also noted that cheap labor does not motivate entrepreneurs to use high technologies in production. In this regard there are disproportions in the sphere of consumption, in particular in the consumption of services in the branches of the social sphere of production, which are becoming increasingly commercial [3].

In such a way these economy disproportions not only contribute to the reduction of human capital (both in the short and long term), but also to its inefficient use.

At the present time, the role of intangible factors of production increases, which makes it possible to talk about human capital not only as an economic resource, but also as an important characteristic of modern social system.

The relevance of the research is determined by the strengthening of the role of digital technologies, not only in everyday life of a person, but also in the principles of modern social system. The concept of anthropological crisis, consisting in the breakdown of traditional social structures, the growth of individualism and tension in relations between cultural and ethnic communities, becomes a "common place" in the diagnosis of modern society. But at the same time, the possibility of critical approaches to society, represented, in particular, by the theory of cognitive capitalism, is not sufficiently taken into account in order to raise the question of the origins of the anthropological crisis and its interrelations with the category of "human capital".

The question of the capitalization of human existence was posed by the founders of this concept (A. Gorz, M. Hardt, A. Negri), but the question of "human capital" transformation under virtualization and digitalization remains crucial and not clear enough [2].

The category "human capital" was first used in 1961, and already in 1965 the American economist Gary Becker formulated the economic content of this definition, which implied the need of additional investments in the living conditions of workers, their retraining and training, which resulted in an increase of efficiency and of quantity and quality of products [18].

According to the paradigm of T. Schultz and G. Becker, "human capital includes the acquired knowledge, motivation, skills, ability and energy that a person is endowed with and that can be used by him for a certain period of time for the production of goods or services" [18].

Little by little, "human capital" began to be understood as the sum total of all costs that do not go directly to production factors, but are a necessary condition for implementation of economic activity, for example, social costs of an enterprise for the construction of kindergartens and hospitals for the families of its employees [5]. A special role in these processes was acquired by financial investments in educational institutions, since it is in the second half of the XX century that the declared autonomy of education from the market is failing. A fixation to maximize the integration of educational strategies and the final product of education, which the future worker must become, is formulated $[7,8]$.

The category "human capital" acquired a special role within the framework of the concept of the "information society", which proclaimed the growth of material resources as the main sources of development [9]. In this situation, these are the abilities and skills of a 
person that became the driving force for further economic and social development, respectively, the person was the main source of investment and financial contributions.

It is to note that the concepts of "human resources", "human capital" and "human potential" used in the scientific literature have both a number of similar properties and differences [6]. Human capital is usually understood as an economic assessment of accumulated knowledge, skills and abilities that a person possesses and which play an important role in increasing labor productivity and promote the development of new technological innovations. It is formed by government and entrepreneurial investments, as well as by self-development of the individual. The most important factor affecting the development of human capital is the level of education, network literacy and general culture of the population.

The innovative character of modern production is associated primarily with the development of the sphere of intangible production, when the main resource is no longer the muscular force, successfully replaced by mechanisms, but creativity, creative abilities inherent to a person. Thus, the reorientation of financial investments by the economic elite from machine-tools to the formation of human capital demonstrates a natural tendency to concentrate efforts on that element of the economic system that turns into a dominant resource. The concentration of the interest on the formation of human capital is accompanied by the creation of a humanistic discourse that promotes and justify the idea that it is human capital and investments in it that become the way to overcome the anthropological crisis. In other words, the development of the corresponding skills and abilities of a person is seen as an instrument for overcoming economic and social contradictions by concentrating on self-realization in the process of creative production.

The model of human capital formation in the conditions of digital transformation of economic systems is shown in Figure 1.

The digital environment, by its very existence, limits the potential for human realization, creates the framework where a modern activist must be inscribed - even at the most banal level of technological equipment and with access to the said sites. Equally important is the economic aspect. Human capital is not a goal in itself, but only a mean to achieve the goals set by the information elite, that is why the virtualization of the work process, transfer of emphases from the creation of material objects to the development of intangible content of virtual reality just changes the set of skills that the performer needs for the qualified execution of the given task.

Another property of human being virtualization is the change in usual space-time coordinates. The existence in the Internet space is freed from the usual framework of space and time, which is fixed by the difference of terms of involvement and engagement. Both of them have the meaning of being involved in something, but they have a significant difference: involvement means physical presence in some place, while engagement is being engaged in a certain system of connections, some community. If for a traditional society, staying in a certain place meant inclusion in the structure of interaction, then with the development of digital technologies, the presence and engagement cease to correspond to each other [13].

As a result, the very "human capital" operating procedure is being transformed. Digitalization transfers human activity to the sphere of virtual production. The question here is not even in the properties of the produced product, but in the very use of the creative potential of a person, focused on the reproduction of predetermined parameters of the realization of his fantasy and willful cravings. 


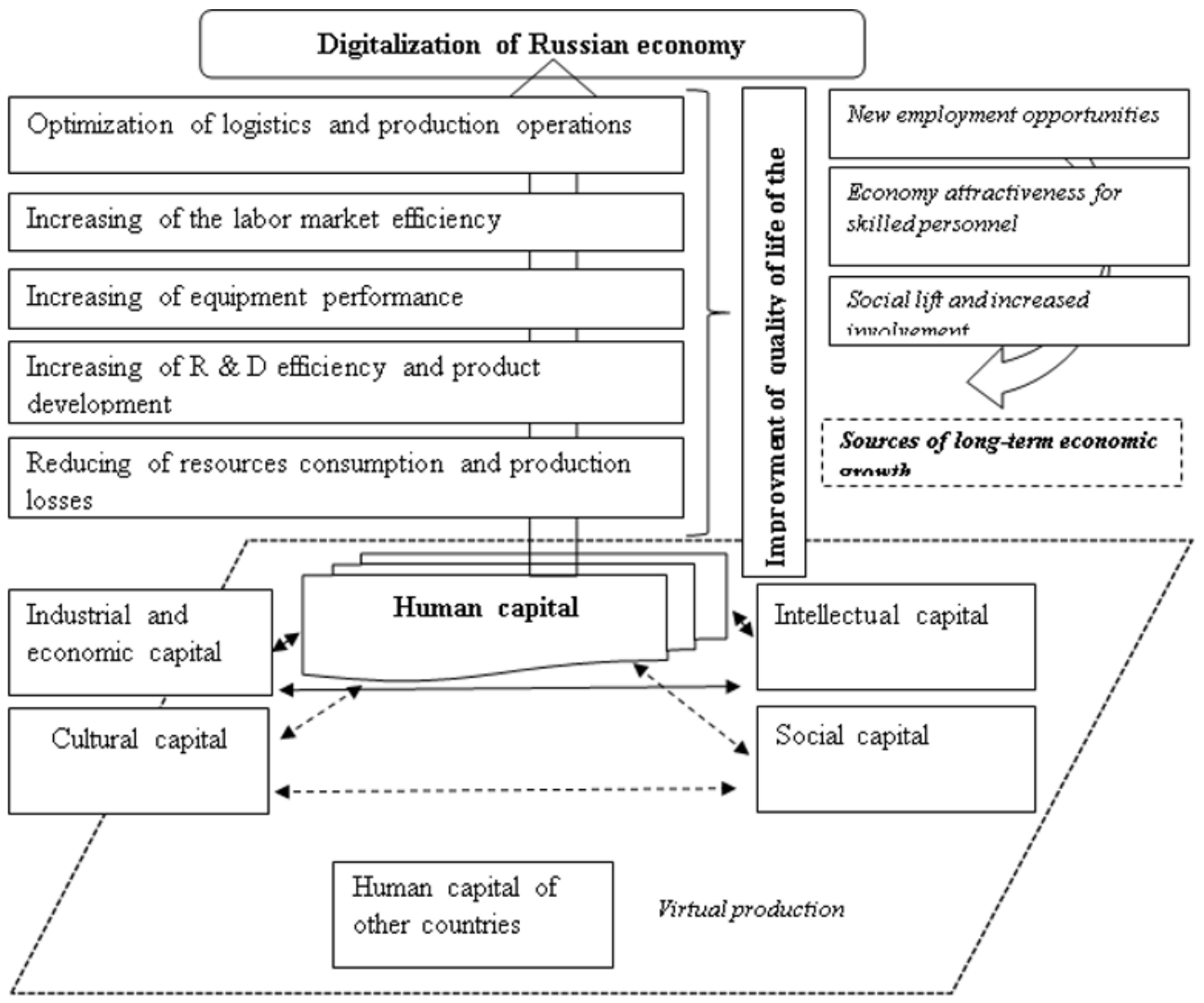

Fig. 1. The model of human capital formation in the conditions of digital transformation of economic systems (prepared by authors)

The development of human capital is significantly influenced by the population standard of living. The quality of life is one of the most important indicators characterizing the level of development of the country. The quality of human life is the most important qualitative and quantitative characteristic of the human capital of the population [7] and includes a set of indicators that determine the ability of a person to work and to live in favorable conditions, the ability of enterprises to increase labor productivity and profit and, as a consequence, the ability of regions and the entire state to increase GDP etc. The development of the human capital of the population is the task of individual, family, and state, as this leads in the long run to the improvement of all micro- and macroeconomic indicators. In the practice of international comparisons, the "Human Development Index" is calculated annually and includes the quantitative parameters of human capital [21].

In Russia, there are a number of barriers that prevent the development and effective use of human capital. To overcome them, it is necessary to reform the incomes of the population which is related to the raising of salaries to at least the subsistence level for all population stratums; it is advisable to consider the possibility of introducing a progressive scale of taxation in Russia; it is necessary to increase significantly the investment in the areas such as education, health care, development of innovative sites, network educational projects; it is necessary to create and to maintain the already existing voluntary organizations of citizens who are able to interact to solve the society problems, to concentrate, express and report social problems, social interests to authorities, including using social networks. 
The most important direction of improving the system of formation and use of human capital is to increase the efficiency and coordination of the activity of formal and informal institutions of regulation of education sector and highly skilled labor market. To make it possible, it is necessary to reduce administrative barriers, review and modify control and supervisory mechanisms, make networking cooperation more flexible and free, which should lead to a reduction of transaction expenses and create a balance between state, private and public interests, taking into account possible changes in social contract between society, business and authorities in the conditions of transition to the digital economy.

An integral element of society human capital is social capital, which includes the bridging capital, which is an institution of trust between dissimilar members of society; bonding capital, arising as a phenomenon of trust in homogeneous groups of society. In the digital economy emerges a new kind of social capital, which can be called network social capital (social and network capital) arising in the process of integratively distributed network interaction of participants in global, national, corporate and social networks. The newest form of social capital (human capital) manifestation are social networks [21]. Regulation and institutionalization of relations between citizens, business and government in social networks is the most important function of the modern state.

By well-coordinated and constructive work of individual citizens, civilian organizations, bodies of government, commercial enterprises, with their equal influence on the formation and development of human capital, Russia can significantly increase its performance in this sphere. Enterprises, state, ordinary people who have the opportunity to influence and to contribute to the development of human capital should understand that a highly educated person, who is the bearer of human capital, plays a leading role in the modern economy and society. The implementation of the goals of sustainable, dynamic innovative development of the country in the digital era depends on living standards of the population, innovative characteristics of specialists, their professional information and network competencies.

In the authors' opinion, the formation of a new quality of human capital corresponding to the emerging realities of the digital society, and its maintaining at a competitive level throughout the working age period of a person's life is possible only in the condition of the life-long education system.

At the same time, on the one hand, some researchers argue that the future belongs to the professions of computer data and information technologies sphere, therefore, the education should be directed towards the formation of professional competencies in science, technology, engineering and mathematics (STEM-competence) [14, 19].

On the other hand, the point of view that the digital future requires human capital of a new quality based on creativity, ability to make unconventional decisions, a so-called creative person, is fully justified.

Formation of matchable professional skills for the digital economy will certainly require more attention to the formation and development of STEM-competencies. The increasing number of opportunities to get a new job and ways to be retained will depend on the ability of workers to understand new technologies and be able to interact with it.

In this regard, it is necessary not to let the moment pass for the retraining of personnel, training of new quality specialists with highly-sought on the labor market STEMcompetencies, first of all, in order to preserve the social stability in the country.

According to statistics in 2016 , about $20 \%$ of all the employed received additional vocational education. The largest number of employees (2.8 million people) received training in professional retraining, advanced training or underwent internships [20].

Professional training in 2016 received 1.8 million people. The least demanded was professional education in the basic professional education programs: 180,800 people underwent such training. The coverage of adult with education isn not uniform regarding age groups. Th essential part of students are people aged 30-49 years [15]. 
In this period of life the employee is most actively involved in the organization production processes, the education received within the basic education programs is no longer sufficient in consequence of the continuous updating of technologies.

The employees of the age of 50-59 years are less likely to receive training, and this can lead to the decrease in the quality of their labor functions. Further, this trend intensifies by aging. Consequently, for the age category from 50 to 64 years special adaptation mechanisms will be required in the digitalization of the economy.

The quality of skills under the transition of digitalization process to a new level of development will constantly change. In this regard, it is the system of the additional professional education, built into the logic of human society transformation on the principles of humanism, that is one of the ways to maintain the quality of human capital at the competitive level.

In order to expand human potential in the field of digital technologies, Russia can also, following the example of other countries, develop a program of attracting specialists (students, teachers, experienced professionals, technological entrepreneurs) from abroad. This will help to eliminate the shortage of qualified personnel in a relatively short time, as well as to develop new competence centers for the most demanded technological areas.

\section{Conclusion}

It is determined that the main drivers of social and economic development are highly educated people, quality and favorable living conditions. Today, the Russian economy being in the process of transition to the digital hypercompetitive level requires highly qualified specialists who are the bearers of human capital, possessing developed information and network properties and competencies, meeting requirements of modern digital economy.

The proposed approach to the understanding of the socio-economic nature of human capital makes it possible to detail the management processes under the economic systems digital transformation. The designated vectors of education systems and personnel professional retraining modernization ensure the achievement of a high level of labor productivity and economic growth of entrepreneurial structures.

The result of the research is the possibility of the practical application of the directions of labor market improvement, development of digital personnel that meet the current economy needs, ensuring the growth of productivity of business structures.

\section{Acknowledgement}

This paper was prepared in the studies for RFBR project No. 18-010-01119 "Management of digital transformation of innovation-industrial cluster as a strategic element of the industrial digital platform: methodology, tools, practice".

\section{References}

1. D. Acemoglu, F. Gallego, J. Robinson. Annual Review of Economics, 6 (1), 875-912 (2014).

2. D. Acemoglu, S. Johnson, J. Robinson. The American Economic Review, 91(5), 13691401 (2001).

3. A.I. Dobrynin, S.A. Dyatlov. Human Capital in a Transitive Economy. (SPb, Science, 2010). 
4. L. Edvinsson. Intellectual Capital. Determination of the true value of the company. (Moscow, Academia, 1999).

5. S.G. Evsukov, A.V. Sigarev, E.V. Ustyuzhanina, E.V. Zaytseva, Journal of Internet Banking and Commerce, 21(6) (2016).

6. E. Glaeser, R. La Porta, F. Lopez-de-Silanes, A. Shleifer. Journal of economic growth, 9(3), 271-303 (2004).

7. T.A. Golovina, I.L. Avdeeva, L.V. Parakhina. Issues of modern economics, 3, 6 (2014).

8. T.A. Golovina, A.V. Polyanin, OV, Rudakova. Bulletin of the Voronezh State University. Series: Economics and Management, 2, 13-18 (2017).

9. A. Gorz. The Intangible. Knowledge, value and capital. (Moscow, State University Higher School of Economics, 2010).

10. Z.R. Khabibullina. Kazan Science, 9, 151-155 (2013).

11. Yu.L. Makarova, A.V. Polyanin. Srednerussky Vestnik Social Sciences, 2 (38), 157162 (2015).

12. URL: http://onlineopen.org/capital-thinks-too

13. URL: Available: www.glass-bead.org/article/960

14. A. Polyanin, L. Pronyaeva, T. Golovina. I. Avdeeva, Y. Polozhentseva. Education Excellence and Innovation Management through Vision 2020: From Regional Development Sustainability to Global Economic Growth, 29th Int. Business Information Management Association Conf. (IBIMA), pp. 2166-2180 (2017).

15. A.V. Polyanin, I.A. Dokukina. Srednerussky Vestnik of Social Sciences, 12(3), 53-63 (2017).

16. A.V. Polyanin, V.V. Gretchin. In the collection: Actual problems of economic development and legal regulation of social and economic relations. Oryol branch of the Russian Academy of National Economy and Public Service, pp. $72-75$ (2013).

17. M.E. Porter. On Competition. Updated and Expanded Ed. Boston (Harvard Business School Publishing, 2008).

18. E.S. Reinert. How Rich Countries Got Rich and Why Poor Countries Stay Poor. (Constable, London, 2007).

19. Russia online: you can not catch up. The Boston Consulting Group (2016).

20. W.J. Schultz. The Moral Conditions of Economic Efficiency. (Cambridge and New York: Cambridge University Press, 2001).

21. Yu.V. Vertakova. Economics and Management, 7(153), 54-64 (2018). 